\title{
Qualidade fisiológica de sementes de pimenta biquinho obtidas de frutos com diferentes graus de maturação e submetidas a condições térmicas
}

Patrícia Cristina do Carmo Oliveira, Andréia Márcia Santos de Souza David, Diego Raphael Rodrigues Botelho, Danúbia Aparecida Costa Nobre, Hugo Tiago Ribeiro Amaro, Maria das Dores da Cruz Souza, Cleisson Dener da Silva

Universidade Estadual de Montes Claros - UNIMONTES, Monte Claros, MG. E-mail: denercleisson5@hotmail.com

\section{Resumo}

O objetivo com este trabalho foi avaliar estádios de maturação dos frutos e a influência de temperatura na qualidade fisiológica de sementes de pimenta biquinho. $O$ trabalho foi dividido em dois estudos, sendo o primeiro (I) relacionado aos diferentes estádios de maturação dos frutos com base na sua coloração (verde, alaranjado, vermelho, vermelho intenso e vermelho intenso murcho). Das sementes extraídas determinouse o teor de água e avaliou-se a qualidade fisiológica por meio dos testes de germinação e vigor (primeira contagem de germinação, emergência de plântulas, índice de velocidade de emergência, comprimento, matéria fresca e seca de plântulas). No segundo (II), destinado para determinar a influência da temperatura nas sementes provenientes de frutos vermelhos e vermelho intenso murchos, foram submetidas a diferentes condições de temperaturas: constante $\left(20,25\right.$ e $\left.30^{\circ} \mathrm{C}\right)$ e alternada $\left(20-30{ }^{\circ} \mathrm{C}\right)$, e novamente avaliadas pelos testes de germinação e vigor. A qualidade fisiológica das sementes de pimenta biquinho é máxima quando os frutos são colhidos com a coloração vermelho intenso e vermelho intenso murcho e, as temperaturas constantes de 25 e $30^{\circ} \mathrm{C}$ são as mais adequadas para avaliação da qualidade fisiológica de sementes.

Palavras-chave: Capsicum chinense; colheita; germinação; vigor.

\section{Physiologic performance of biquinho pepper seeds of fruit with different maturation degrees and submitted to thermal stress}

\begin{abstract}
The objective of this work was to evaluate fruit ripening stages and the influence of temperature on the physiological quality of red pepper seeds. The work was divided in two studies, the first one (I) related to the different maturation stages of the fruits based on their coloration (green, orange, red, intense red and deep red withered). From the seeds extracted, the water content was determined and the physiological quality was evaluated through the tests of germination and vigor (first germination count, seedling emergence, emergence speed index, length, fresh and dry matter of seedlings). In the second (II), to determine the influence of the temperature on the seeds of red fruits and intense red withered, were submitted to different temperature conditions: constant $\left(20,25\right.$ and $\left.30{ }^{\circ} \mathrm{C}\right)$ and alternating $\left(20-30{ }^{\circ} \mathrm{C}\right)$, and again evaluated by germination and vigor tests. The physiological quality of the coriander seeds is maximal when the fruits are harvested with intense red coloration and deep red withering, and the constant temperatures of 25 and $30^{\circ} \mathrm{C}$ are the most adequate for evaluating the physiological quality of seeds.
\end{abstract}

Keywords: Capsicum chinense Jacquin.; harvest; germination; vigor.

\section{Introdução}

Dentre as diversas espécies de pimenta cultivadas no Brasil, a pimenta biquinho
(Capsicum chinense Jacquin) é caracterizada pelo sabor, aroma e alto valor nutricional, por isso ganhou rápida expressão nacional. Além disso, o 
uso na ornamentação se deve pela a presença de frutos de coloração intensa que contrastam com a folhagem; seus frutos de sabor doce e sem pungência, são arredondados estreitando-se completamente na ponta, tamanho pequeno e de coloração vermelho intenso ou amarelo (CARVALHO et al., 2006; MOREIRA et al., 2006).

O cultivo da pimenta deve se iniciar com a utilização de sementes de alta qualidade. Portanto, o momento da colheita dos frutos é um dos requisitos que deve ser levado em consideração, visto que, em espécies de crescimento indeterminado, como é o caso da pimenta, o florescimento e a frutificação são contínuos, e são encontrados na mesma planta frutos em diferentes estádios de maturação, o que dificulta a determinação da época de maturidade fisiológica das sementes e o momento ideal para a colheita (PEREIRA et al., 2014).

O processo de maturação das sementes de pimenta ocorre mesmo antes da maturação do fruto (mudança da coloração do exocarpo dos frutos de verde para vermelha), neste momento, as sementes já podem alcançar a maturidade fisiológica, quando atingem o máximo de germinação e vigor (SILVA et al., 2009). Para as sementes de algumas cultivares de pimenta, a colheita pode ser iniciada, aproximadamente, aos 60 dias após o florescimento, ou quando mais de $80 \%$ dos frutos estiverem mudando de cor (NASCIMENTO et al., 2006). Para Vidigal (2009), a qualidade fisiológica das sementes foi máxima entre 65 e 70 após o florescimento, quando os frutos estavam com a cor vermelha e vermelha intensa.

Nesse contexto, o uso de sementes colhidas no momento ideal, favorece a qualidade final, promovendo uniformidade e, por consequência, elevada produtividade. No entanto, conforme Carvalho e Nakagawa (2012), a semente é influenciada por diversos fatores, sendo a temperatura um dos mais importantes, afetando a germinação total e a velocidade de germinação, pois tende a atuar na velocidade de absorção de água e nas reações bioquímicas no processo germinativo.

A temperatura considerada ótima é aquela na qual a semente expressa seu máximo de germinação. Nesta perspectiva, há espécies nas quais a germinação das sementes é favorecida por temperatura constante (PACHECO et al., 2010), por alternância de temperaturas, à semelhança do que acontece em condições naturais (LIMA et al., 2011).

De acordo com as Regras para Análise de Sementes (Brasil, 2009), a temperatura prescrita para avaliação da germinação das sementes do gênero Capsicum é $20-30{ }^{\circ} \mathrm{C}$ alternada. Entretanto, é baixa a porcentagem de sementes que são germinadas nessas condições, além de se observar desuniformidade na germinação, justificando assim necessidade de estudos que permitam a reavaliação dos fatores que afetam o processo germinativo da espécie.

Assim, o objetivo deste estudo foi avaliar o efeito dos estádios de maturação do fruto e condições de temperaturas na qualidade fisiológica de sementes de pimenta biquinho.

\section{Material e Métodos}

Foram conduzidos dois experimentos no Laboratório de Análise de Sementes da Universidade Estadual de Montes Claros, Campus Janaúba, MG. No primeiro estudo (I), foi avaliado o efeito do estádio de maturação do fruto para a qualidade fisiológica de sementes de pimenta biquinho. Após 20 dias, foi conduzido o segundo estudo (II), destinado para avaliar o efeito da temperatura na germinação e no vigor das sementes.

\section{Estudo (I)}

Com o objetivo de avaliar o efeito do estádio de maturação do fruto na qualidade fisiológica de sementes de pimenta biquinho, utilizaram-se sementes oriundas de frutos em diferentes estádios de maturação, classificados como: frutos verdes, alaranjados, vermelhos, vermelho intenso e vermelho intenso murchos. As sementes foram extraídas dos frutos manualmente, lavadas em água corrente por cinco minutos, e posteriormente, foram secadas em condições ambientais de laboratório $\left( \pm 26^{\circ} \mathrm{C}\right.$ e $50 \%$ UR), por aproximadamente $48 \mathrm{~h}$, para remoção da água superficial.

Nas sementes recém extraídas dos frutos, determinou-se o teor de água pelo método de estufa, a temperatura de $105 \pm 3{ }^{\circ} \mathrm{C}$, durante 24 horas, com quatro repetições de $30 \mathrm{~g}$ de sementes, sendo os resultados expressos em porcentagem (BRASIL, 2009).

Para $O$ teste de germinação, foram utilizadas quatro repetições de 50 sementes, distribuídas sobre duas folhas de papel germitest, umedecidas com água destilada, em volume equivalente a 2,5 vezes o peso do papel seco, em 
caixas plásticas do tipo gerbox. As caixas foram colocadas em germinador sob temperatura de 25 ${ }^{\circ} \mathrm{C}$. As avaliações foram realizadas em duas contagens: primeira contagem da germinação, determinado pelo número de plântulas normais no sétimo dia após a instalação do teste; e avaliação final, que consistiu na contagem de plântulas normais e anormais, sementes mortas e dormentes no décimo quarto dia, com os resultados expressos em porcentagem (BRASIL, 2009). Vale ressaltar que esta espécie não está descrita nas regras para análise de sementes, sendo relatado apenas o gênero Capsicum.

O teste de emergência de plântulas foi realizado com quatro repetições de 50 sementes que foram semeadas a $0,5 \mathrm{~cm}$ de profundidade, em caixas plásticas do tipo gerbox, contendo areia lavada, esterilizada e umedecida a $50 \%$ da capacidade de retenção (BRASIL, 2009). As caixas foram mantidas em condições ambientais de laboratório $\left(26^{\circ} \mathrm{C}\right)$. Os resultados foram obtidos pelo número de plântulas normais adotando-se como critério de avaliação, as plântulas que apresentavam estruturas essenciais (sistema radicular, parte aérea, cotilédones) desenvolvidas e completas, no décimo quarto dia após a semeadura, com resultados expressos em porcentagem de emergência de plântulas.

$O$ índice de velocidade de emergência (IVE) foi determinado a partir de contagens diárias do número de plântulas emergidas até 14 dias após a semeadura. Ao final do teste, foi calculado o IVE empregando-se a fórmula proposta por Maguire (1962).

Foi determinado o comprimento de plântulas, junto ao teste de emergência, com o auxílio de uma régua milimetrada, mensurandose o comprimento total (raiz primária até parte aérea) com os resultados expressos em $\mathrm{mm} /$ plântula. Para a obtenção de massa fresca e seca as plântulas foram pesadas em balança com precisão de 0,001 g. Em seguida, as plântulas de cada repetição foram colocadas em sacos de papel e levadas para secar em estufa com circulação forçada de ar, a $65{ }^{\circ} \mathrm{C}$ constante, por $72 \mathrm{~h}$ horas para a determinação da matéria seca. Após este período, as amostras foram colocadas para resfriar no dessecador e novamente pesadas em balança de precisão, os resultados médios foram expressos em miligramas.

\section{Estudo (II)}

Após a separação dos frutos foi constatado que sementes provenientes de frutos vermelhos e vermelho intenso murchos, por apresentarem melhor desempenho fisiológico em relação aos demais estádios de maturação no estudo (I), foram então selecionadas para avaliação da qualidade fisiológica das mesmas.

Os testes de germinação e vigor (primeira contagem de germinação) foram realizados em quatro condições de temperatura, 20,25 e $30^{\circ} \mathrm{C}$ constantes e $20-30{ }^{\circ} \mathrm{C}$ alternada, nas mesmas condições descritas no estudo (I).

\section{Análise dos dados}

O delineamento experimental utilizado em ambos os experimentos foi o inteiramente casualizado. Para o primeiro estudo (I), os tratamentos consistiram nos cinco estádios de maturação dos frutos (verde, alaranjado, vermelho, vermelho intenso e vermelho intenso murcho) e, para o estudo (II), utilizou-se o esquema fatorial $2 \times 4$ (dois estádios de maturação do fruto e quatro temperaturas). Os dados para os dois experimentos foram submetidos à análise de variância e teste "F", com médias comparadas pelo teste Tukey, a 5\% de probabilidade.

\section{Resultados e Discussão Estudo (I)}

Como procedimento inicial na realização da pesquisa, os resultados indicaram que a variação máxima nos teores de água das sementes dos diferentes estádios de maturação do fruto, foi de 1,3 pontos percentuais, após a secagem (Tabela 1). Nota-se que as os teores de água, estavam próximos ao esperado, de $10 \%$ de umidade, encontrando-se dentro dos limites considerados ideais para aplicação dos testes.

O baixo teor de água para sementes ortodoxas é imprescindível na padronização das avaliações e obtenção de resultados consistentes (TOKUHISA et al., 2008). Desse modo, sementes de Capsicum, consideradas ortodoxas, possuem a capacidade de tolerar a dessecação (QUEIROZ, 2009), sem danos irreversíveis, reduzindo a atividade metabólica quando secas, o que pode aumentar sua longevidade, além de conferir tolerância a condições ambientais extremas (LEPRINCE; BUITINK, 2010). 
Tabela 1. Teores médios de água das sementes de pimenta biquinho em função da coloração para cada estádio de maturação do fruto.

\begin{tabular}{lc}
\hline Estádio de maturação do fruto & Teor de água (\%) \\
\hline Verde & 11,3 \\
Alaranjado & 9,4 \\
Vermelho & 9,2 \\
Vermelho intenso & 9,0 \\
Vermelho intenso murcho & 9,0 \\
\hline
\end{tabular}

Houve efeito significativo $(p<0,05)$ do estádio de maturação dos frutos sobre a qualidade fisiológica das sementes avaliadas (Tabela 2). Em relação ao teste de primeira contagem de germinação, nota-se maior vigor das sementes nos estádios mais avançados de maturação dos frutos (vermelho intenso e vermelho intenso murcho), estatisticamente semelhantes aos frutos vermelhos. De acordo com Munizzi et al. (2010), sementes com maior qualidade fisiológica apresentam maior velocidade nos processos metabólicos, promovendo germinação mais rápida e maior uniformidade na emergência de plântulas. Valores nulos na primeira contagem de germinação foram observados para as sementes extraídas de frutos verdes (Tabela 2), estatisticamente inferiores aos demais estádios de maturação.

Os resultados obtidos para a variável germinação indicaram que os maiores percentuais foram obtidos em sementes provenientes de frutos vermelho intenso e vermelho intenso murcho (Tabela 2). Ainda para esses mesmos estádios é possível observar baixos valores de plântulas anormais, sementes mortas e dormentes, o que pode ser explicado principalmente pelo acúmulo de reservas necessárias ao processo de germinação, nos estádios mais avançados de maturação (vermelho intenso e vermelho intenso murcho).

Para sementes de frutos verdes, observase que a germinação foi nula, justificando as altas porcentagens encontradas de sementes mortas e dormentes (Tabela 2). Esses resultados podem estar associados à imaturidade do embrião, além da falta de reservas necessárias para o processo de germinação (ABUD et al., 2013). Em adição, Justino et al. (2010) ressaltam que a falta de germinação de pimentas nos estádios iniciais de maturação do fruto pode estar associada a presença de dormência nas sementes, o que afeta diretamente seu real potencial germinativo.

Tabela 2. Primeira contagem de germinação (PCG), Germinação (GER), plântulas anormais (PA) sementes mortas (SM) e sementes dormentes (SD) de pimenta biquinho em função do estádio de maturação do fruto.

\begin{tabular}{lccccc}
\hline \multirow{2}{*}{ Estádio de maturação do fruto } & \multicolumn{5}{c}{ Variáveis (\%) } \\
\cline { 2 - 6 } & PCG & GER & PA & SM & SD \\
\hline Verde & O,0 C & $0,0 \mathrm{D}$ & $2,0 \mathrm{~B}$ & $69,0 \mathrm{~A}$ & $29,0 \mathrm{~A}$ \\
Alaranjado & $8,0 \mathrm{~B}$ & $43,0 \mathrm{C}$ & $22,0 \mathrm{~A}$ & $11,0 \mathrm{~B}$ & $24,0 \mathrm{AB}$ \\
Vermelho & $21,0 \mathrm{AB}$ & $59,0 \mathrm{~B}$ & $17,0 \mathrm{~A}$ & $7,0 \mathrm{~B}$ & $17,0 \mathrm{~B}$ \\
Vermelho intenso & $30,0 \mathrm{~A}$ & $83,0 \mathrm{~A}$ & $6,0 \mathrm{~B}$ & $4,0 \mathrm{~B}$ & $7,0 \mathrm{C}$ \\
Vermelho intenso murcho & $33,0 \mathrm{~A}$ & $82,0 \mathrm{~A}$ & $8,0 \mathrm{~B}$ & $5,0 \mathrm{~B}$ & $5,0 \mathrm{C}$ \\
\hline CV (\%) & 29,0 & 10,4 & 39,6 & 18,8 & 20,9
\end{tabular}

Médias seguidas por letras diferentes, na coluna, diferem $(p<0,05)$ pelo teste Tukey.

Os resultados encontrados no presente estudo corroboram com os obtidos por Abud et al. (2013), os quais verificaram que sementes das pimentas malagueta e biquinho extraídas de frutos verdes não germinaram, enquanto que aquelas obtidas de frutos vermelhos tiveram 
germinação significativamente superior, atingindo percentuais máximos de $89 \%$ para pimenta biquinho aos 79 dias após a antese e $86 \%$ para pimenta malagueta aos 71 dias após a antese.

Pelos padrões nacionais para produção e comercialização de sementes de pimenta, a porcentagem de germinação mínima deve ser de $70 \%$ para sementes básicas e de $80 \%$ para as certificadas de primeira e segunda geração, bem como para as sementes S1 e S2, conforme a Instrução Normativa de 5 de setembro de 2012 (BRASIL, 2012). No presente estudo verificou-se que para as sementes oriundas de frutos vermelho intenso e vermelho intenso murchos todos os percentuais de germinação foram superados aos valores mínimos citados anteriormente. No entanto, para os demais estádios, os valores foram inferiores ao padrão mínimo exigido comercialmente para todas as categorias, ressaltando a importância do momento ideal de colheita de sementes.

A porcentagem de plântulas anormais oriundas de sementes de frutos verdes, vermelho intenso e vermelho intenso murchos foi inferior em comparação às sementes de frutos vermelhos e alaranjados (Tabela 2), entretanto, para a variável sementes mortas os valores observados nos frutos verde foram superiores, sendo que os demais estádios não diferiram entre si. Este fato pode ser explicado devido à não maturação do embrião, já que, de acordo com Caixeta et al. (2014), os sistemas de membranas celulares ainda não apresentam uma estruturação ideal, ocorrendo, portanto, uma maior lixiviação de exsudatos, durante o processo de embebição, devido à maior permeabilidade do tegumento, prejudicando dessa forma o desempenho do processo germinativo.

Cabe salientar que com o avanço do processo de maturação do fruto, houve uma redução na porcentagem de sementes dormentes (Tabela 2), demonstrando, a importância do ponto ideal de colheita das sementes com base na maturidade fisiológica.

Em relação ao vigor das sementes, notase que houve influência significativa dos estádios de maturação do fruto sobre as variáveis analisadas, exceto para o comprimento de plântulas (Tabela 3).

Tabela 3. Emergência de plântulas (EP), índice de velocidade de emergência (IVE), massa fresca (MF) e massa seca da parte aérea (MS), oriundas de sementes de pimenta biquinho em função do estádio de maturação do fruto.

\begin{tabular}{lcccc}
\hline Estádio de maturação dos frutos & \multicolumn{4}{c}{ Variáveis } \\
\cline { 2 - 5 } & EP (\%) & IVE & MF (mg) & MS (mg) \\
\hline Verde & $3,0 \mathrm{D}$ & $0,1 \mathrm{C}$ & $9,7 \mathrm{~B}$ & $1,5 \mathrm{C}$ \\
Alaranjado & $24,0 \mathrm{C}$ & $1,1 \mathrm{C}$ & $11,8 \mathrm{AB}$ & $2,1 \mathrm{BC}$ \\
Vermelho & $43,0 \mathrm{~B}$ & $2,9 \mathrm{~B}$ & $13,0 \mathrm{~A}$ & $2,5 \mathrm{~B}$ \\
Vermelho intenso & $71,0 \mathrm{~A}$ & $4,2 \mathrm{~A}$ & $14,5 \mathrm{~A}$ & $4,2 \mathrm{~A}$ \\
Vermelho intenso murcho & $73,0 \mathrm{~A}$ & $4,4 \mathrm{~A}$ & $14,0 \mathrm{~A}$ & $4,0 \mathrm{~A}$ \\
\hline CV (\%) & 7,6 & 26,2 & 11,4 & 15,7
\end{tabular}

Médias seguidas por letras diferentes, na coluna, diferem $(p<0,05)$ pelo teste Tukey.

De maneira semelhante ao teste de germinação e primeira contagem, os resultados dos testes de emergência de plântulas, IVE, massa fresca e seca de plântulas, indicaram melhor qualidade fisiológica para as sementes procedentes de frutos vermelho intenso e vermelho intenso murchos (Tabela 3 ).
Conforme Gomes et al. (2017), o parâmetro de acúmulo de matéria seca não estima corretamente a maturidade das sementes, sendo a mudança de coloração dos frutos a melhor estratégia para obter alto potencial fisiológico. No entanto, na presente pesquisa, foi possível comprovar que a maior qualidade fisiológica para sementes de pimenta biquinho foi 
expressa em frutos vermelho intenso e vermelho intenso murchos, que também obtiveram maiores teores de matéria seca. Esses resultados vão de encontro aos apresentados por Ruiz e Parera (2017), onde relatam o momento ideal de colheita para frutos de pimentões visando a qualidade de sementes, coincidente com a mudança de coloração do fruto para o vermelho.

\section{Estudo (II)}

Diante dos resultados obtidos no estudo I indicando os frutos vermelho intenso e vermelho intenso murchos como aqueles que apresentam sementes com maior qualidade fisiológica, o estudo II foi conduzido e os resultados da análise de variância revelou que não houve interação $(p>0,05)$ entre os fatores estádio de maturação e temperatura para nenhuma das variáveis estudadas, justificando-se somente a apresentação do efeito isolado de cada fator.

Com exceção de sementes mortas, as demais variáveis foram afetadas de modo significativo pelas temperaturas estudadas (Tabela 4). O vigor das sementes, avaliado por meio do teste de primeira contagem, foi nulo quando as sementes foram submetidas às temperaturas de $20{ }^{\circ} \mathrm{C}$ constante e $20-30{ }^{\circ} \mathrm{C}$ alternada (Tabela 4). Para Carvalho e Nakagawa (2012) baixas temperaturas reduzem a velocidade de germinação das sementes.
Ainda conforme a Tabela 4, verificou-se aumento significativo na primeira contagem da germinação das sementes ao serem submetidas à temperatura de $25{ }^{\circ} \mathrm{C}$, enquanto para a temperatura de $30{ }^{\circ} \mathrm{C}$, os valores obtidos foram intermediários. $\mathrm{O}$ teste de primeira contagem de germinação fundamenta-se no pressuposto de que as sementes mais vigorosas germinam mais rápido (ABUD et al., 2013).

Para a variável germinação, observa-se que à medida que se elevou a temperatura, houve incrementos significativos na porcentagem de germinação, com exceção da temperatura alternada de $20-30{ }^{\circ} \mathrm{C}$, denotando que a espécie requer temperaturas mais altas durante 0 processo germinativo, revelando a importância das condições adequadas de temperatura para os testes de germinação de pimenta biquinho.

Nota-se ainda que a germinação das sementes submetidas às temperaturas de 25 e 30 ${ }^{\circ} \mathrm{C}$ constantes foi superior em relação à temperatura alternada $\left(20-30{ }^{\circ} \mathrm{C}\right)$, indicada para o gênero Capsicum, conforme Brasil (2009). Em relação à temperatura alternada $\left(20-30{ }^{\circ} \mathrm{C}\right)$, a condição de $30{ }^{\circ} \mathrm{C}$ constante proporcionou incrementos superiores a $500 \%$ na porcentagem de germinação das sementes (Tabela 4).

Tabela 4. Primeira contagem de germinação (PCG), germinação (GER), plântulas anormais (PA) e sementes dormentes (SD) de pimenta biquinho provenientes de frutos vermelho intenso e vermelho intenso e murchos, em diferentes temperaturas.

\begin{tabular}{lcccc}
\hline \multirow{2}{*}{ Temperatura $\left({ }^{\circ} \mathrm{C}\right)$} & \multicolumn{4}{c}{ Variáveis (\%) } \\
\cline { 2 - 5 } & PCG & GER & PA & SD \\
\hline 20 & $0,0 \mathrm{C}$ & $3,0 \mathrm{~B}$ & $41,0 \mathrm{~A}$ & $53,0 \mathrm{~B}$ \\
25 & $25,0 \mathrm{~A}$ & $73,0 \mathrm{~A}$ & $12,0 \mathrm{~B}$ & $10,0 \mathrm{C}$ \\
30 & $8,0 \mathrm{~B}$ & $80,0 \mathrm{~A}$ & $12,0 \mathrm{~B}$ & $6,0 \mathrm{C}$ \\
$20-30$ & $0,0 \mathrm{C}$ & $12,0 \mathrm{~B}$ & $4,0 \mathrm{~B}$ & $77,0 \mathrm{~A}$ \\
\hline CV (\%) & 22,9 & 18,6 & 29,4 & 27,6 \\
\hline
\end{tabular}

Médias seguidas por letras diferentes, na coluna, diferem $(p<0,05)$ pelo teste Tukey.

Teixeira et al. (2018), relataram que a melhor temperatura para a germinação de sementes de pimenta malagueta (Capsicum frutescens $\mathrm{L}$.) foi de $25^{\circ} \mathrm{C}$ constante, e indicaram a necessidade de maiores estudos para verificar a ocorrência de germinação satisfatória nas temperaturas entre 20 e $30^{\circ} \mathrm{C}$.
Para a presente pesquisa, os resultados encontrados revelam que as temperaturas de 25 e $30{ }^{\circ} \mathrm{C}$ constantes para a pimenta biquinho (Capsicum chinense) mostraram-se mais adequadas para a condução dos testes de germinação em relação àquela descrita por Brasil (2009) para o gênero Capsicum. 
Maiores médias de plântulas anormais foram observadas na condição de $20{ }^{\circ} \mathrm{C}$, enquanto que as demais temperaturas não diferiram entre si (Tabela 4). Verifica-se também que, o regime de temperatura alternada (20-30 $\left.{ }^{\circ} \mathrm{C}\right)$ promoveu aumento na porcentagem de sementes dormentes.

Nas condições de temperaturas alternadas $\left(20-30{ }^{\circ} \mathrm{C}\right)$, a recomendação (Brasil, 2009) é que as sementes permaneçam por um período de horas em temperatura baixa $\left(20^{\circ} \mathrm{C}\right)$. Nesse sentido, Bewely e Blak (1994) ressaltam que temperaturas baixas $\left(20^{\circ} \mathrm{C}\right)$ podem diminuir a capacidade da semente em absorver água, limitando as atividades de várias vias metabólicas e reduzindo o processo germinativo.

A temperatura interfere ainda no desenvolvimento das plântulas e no estande final das mesmas. Por outro lado, os altos valores verificados na porcentagem de sementes dormentes para as condições de $20^{\circ} \mathrm{C}$ constante e $20-30{ }^{\circ} \mathrm{C}$ alternadas podem estar associados à dormência. Sementes do gênero Capsicum apresentam germinação lenta e irregular mesmo sob condições favoráveis (LAKSHMANAN; BERKE, 1998).

Para Borges e Rena (1993), as sementes de algumas espécies germinam melhor no regime de temperatura constante, tal exigência corresponde a uma adaptação as flutuações naturais do ambiente.

O efeito do estádio de maturação do fruto foi significativo $(p<0,05)$ apenas para a variável plântulas anormais (Tabela 5), sendo os resultados superiores para os frutos de coloração vermelho intenso.

Tabela 5. Resultados médios de plântulas anormais de pimenta biquinho, em função do estádio de maturação do fruto.

Estádio de maturação do fruto

Vermelho intenso

Vermelho intenso murcho
Plântulas anormais (\%)

$21,0 \mathrm{~A}$

$14,0 \mathrm{~B}$

Médias seguidas por letras diferentes, na coluna, diferem $(P<0,05)$ pelo teste Tukey.

Vidigal et al. (2009) observaram que as sementes provenientes de frutos de pimenta $(C$. annuum) colhidos com coloração vermelho $e$ vermelho intenso, apresentaram uma melhor qualidade fisiológica, sendo as sementes de frutos vermelho intenso mais expressivas. $O$ que não foi observado na presente pesquisa, ao se comparar a qualidade das sementes de pimenta biquinho ( $C$. chinense), portanto, a qualidade fisiológica das sementes está relacionada com a espécie.

\section{Conclusão}

A qualidade fisiológica das sementes de pimenta biquinho é máxima quando os frutos são colhidos com a coloração vermelho intenso e vermelho intenso murchos e, as temperaturas constantes de 25 e $30{ }^{\circ} \mathrm{C}$ são as mais adequadas para avaliação da qualidade fisiológica de sementes.

\section{Referências}

ABUD, H.F.; ARAÚJO, E.F.; ARAÚJO, R.F.; ARAÚJO, A.V.; PINTO, C.M.F. Qualidade fisiológica de sementes das pimentas malagueta e biquinho durante a ontogênese. Pesquisa Agropecuária Brasileira, v.48, n.12, p.1546-1554, 2013. https://doi.org/10.1590/50100204X2013001200003

BEWELEY, J.D.; BLACK, M. Seeds: physiology of development and germination. 2. ed. New York: Plenum, 1994. $445 p$. https://doi.org/10.1007/978-1-4899-1002-8 9

BORGES, E.E.L.; RENA, A.B. Germinação de sementes. In: AGUIAR, I.B.; PIÑA-RODRIGUES, F.C.M.; FIGLIOLA, M.B. Sementes florestais tropicais. Brasília, DF: Associação Brasileira de Tecnologia de Sementes, 1993. p. 83-135.

BRASIL. Ministério da Agricultura, Pecuária e Abastecimento. Portaria no 111 , de 4 de setembro de 2012. Estabelece os padrões de identidade e qualidade para a produção e a comercialização de sementes de espécies olerícolas, condimentares, medicinais e aromáticas, disposto em anexo. Diário Oficial 
[da] República Federativa do Brasil, 5 set. 2012. Seção 1, p.3-4.

BRASIL. Ministério da Agricultura, Pecuária e Abastecimento. Regras para análise de sementes. Brasília: Mapa/ACS, 2009. 395p.

CAIXETA, F.; VON PINHO, E.V.R.; GUIMARÃES, R.M.; PEREIRA, P.H.A.R.; CATÃO, H.C.R.M.; CLEMENTE, A.C.S. Determinação do ponto de colheita na produção de sementes de pimenta malagueta e alterações bioquímicas durante o armazenamento e a germinação. Revista Científica, v.42, n.2, p.187-197, 2014. https://doi.org/10.15361/1984-

5529.2014v42n2p187-197

CARVALHO, N.M.; NAKAGAWA, J. Sementes: ciência, tecnologia e produção. 5. ed. Jaboticabal: FUNEP, 2012. 590p.

CARVALHO, S.I.C.; BIANCHETTI, L.B; RIBEIRO, C.S.C.; LOPES, C.A. Pimentas do gênero Capsicum no Brasil. Brasília: Embrapa Hortaliças, 2006. (Documentos, 94)

GOMES, G.P.; DAMASCENO JUNIOR, C.V.; COSTA, D.S.; QUEIROZ, R.A.; BABA, V.Y.; TAKAHASHI, L.S.A.; GONÇALVES, L.S.A. Época de colheita dos frutos e potencial fisiológico das sementes de pimenta 'dedo-de-moça BRS Mari'. Semina: Ciências Agrárias, v.38, n.6, p.3897-3906, 2017. https://doi.org/10.5433/1679-

0359.2017v38n6p3897

JUSTINO, E.V.; AMARAL-LOPES, A.C.; NASCIMENTO, W.M. Efeito da maturação e do armazenamento na qualidade fisiológica de sementes de pimenta BRS Mari. Horticultura Brasileira, v.28, n.2, p.4347-4353, 2010.

LAKSHMANAN, V.; BERKE, T.G. Lack of primary seed dormancy in pepper (Capsicum spp.). Capsicum and Eggplant Newsletter, v.17, n.1, p.72-75, 1998.

LEPRINCE, O.; BUITINK, J. Desiccation tolerance: from genomics to the field. Plant Science, v.179, n.6, p.554-564, 2010. https://doi.org/10.1016/i.plantsci.2010.02.011

LIMA, C.R.; PACHECO, M.V.; BRUNO, R.L.A.; FERRARIA, C.S.; BRAGA JÚNIOR, J.M.; BEZERRA, A.K.D. Temperaturas e substratos na germinação de sementes de Caesalpinia pyramidalis Tul. Revista Brasileira de Sementes, v.33, n.2, p.216222, 2011. http://dx.doi.org/10.1590/S0101$\underline{31222011000200003}$

MAGUIRE, J.A. Speed of germination: aid in selection and evaluation for seedling emergence and vigor. Crop Science, v.2, p.176-177, 1962. https://doi.org/10.2135/cropsci1962.0011183X0 $\underline{00200020033 x}$

MOREIRA, G.R.; CALIMAN, F.R.B.; SILVA, D.J.H.; COSTA, C.S. Espécies e variedades de pimenta. Informe Agropecuário, v.27, n.235, p.16-29, 2006.

MUNIZZI, A.; BRACCINI, A.L.; RANGEL, M.A.S.; SCAPIM, C.A.; ALBRECHT, L.P. Qualidade de sementes de quatro cultivares de soja, colhidas em dois locais no estado de Mato Grosso do Sul. Revista Brasileira de Sementes, v.32, n.1, p.176185, 2010. http://dx.doi.org/10.1590/S0101$\underline{31222010000100020}$

NASCIMENTO, W.M.; DIAS, D.C.F.S.; FREITAS, R.A. Produção de sementes de pimentas. Informe Agropecuário, v.27, n.235, p.30-39, 2006.

PACHECO, M.V.; MATTEI, V.L.; MATOS, V.P.; SENA, L.H.M. Germination and vigor of Dimorphandra mollis Benth. seeds under different temperatures and substrates. Revista Árvore, v.34, n.2, p.205-213, 2010. http://dx.doi.org/10.1590/S0100$\underline{67622010000200002}$

PEREIRA, F.E.C.B.; TORRES, S.S.; LIMA SILVA, M.I.L.; GRANGEIRO, L.C.; BENEDITO, C.P. Qualidade fisiológica de sementes de pimenta em função da idade e do tempo de repouso póscolheita dos frutos. Revista Ciência Agronômica, v.45, n.4, p.737-744, 2014. https://doi.org/10.1590/S180666902014000400011

QUEIROZ, L.A.F. Estádio de maturação e secagem na qualidade fisiológica de sementes de pimenta habanero yellow (Capsicum chinense Jacquin) e malagueta (Capsicum frutescens L.). 2009. Tese (Doutorado em Fitotecnia) - Departamento de Agricultura, Universidade Federal de Lavras, Lavras, 2009. 
RUIZ, M.B.; PARERA, C.A. Effect of harvesting time on seed quality of two bell pepper cultivars (Capsicum annuum). Revista de la Facultad de Ciencias Agrarias, v.49, n.2, p.67-77, 2017.

SILVA, R.F.; ARAÚJO, E.F.; VIGGIANO, J. Extração de sementes de frutos carnosos de hortaliças. In: NASCIMENTO, W.M. Tecnologia de sementes de hortaliças. Brasília, DF: Embrapa Hortaliças, 2009. p. 77-102.

TEIXEIRA, S.B.; COCCO, K.S.T.; CELENTE, A.M.; DELIAS, D.S.; REOLON, F.; MORAES, D.M. Efeito da temperatura sobre a germinação e crescimento inicial de sementes de Capsicum frutescens (L.). Revista Verde de Agroecologia e Desenvolvimento Sustentável, v.13, n.1, p.58-65, 2018.

http://dx.doi.org/10.18378/rvads.v13i1.5026

TOKUHISA, D.; DIAS, D.C.F.S.; ALVARENGA, E.M.; DIAS, L.A.S.; MARIN, S.L.D. Época de colheita dos frutos e ocorrência de dormência em sementes de mamão (Carica papaya L.). Revista Brasileira de Sementes, v.30, n.2, p.75-80, 2008. http://dx.doi.org/10.1590/S0101-

$\underline{31222008000200010}$

VIDIGAL, D.S.; SANTOS, D.C.F.; VON PINHO, E.V.R.; DIAS, L.A.S. Alterações fisiológicas e enzimáticas durante a maturação de sementes de pimenta (Capsicum annuum L). Revista Brasileira de Sementes, v.31, n.2, p.129-136, 2009. http://dx.doi.org/10.1590/S0101-

$\underline{31222009000200015}$ 